Revista Brasileira de Agricultura Irrigada v.5, $\mathrm{n}^{\circ} .1$, p.63-67, 2011

ISSN 1982-7679 (On-line)

Fortaleza, CE, INOVAGRI - http://www.inovagri.org.br/rbai

Protocolo 04009 - 09/10/2010 Aprovado em 03/03/2011

\title{
EFEITO DE TIPOS DE ADUBAÇÃO E LÂMINAS DE ÁGUA SALINA EM FOLHAS DE PINHÃO MANSO EM CONDIÇOES DE CAMPO
}

\author{
Jerônimo Andrade da Nóbrega ${ }^{\mathbf{1}}$, Carlos Alberto Vieira de Azevedo ${ }^{2}$, José Dantas Neto ${ }^{3}$, \\ Joab Josemar Vitor Ribeiro do Nascimento ${ }^{4}$, Gilberto da Cruz Gouveia Neto ${ }^{5}$

\footnotetext{
${ }^{1}$ Doutorando em Engenharia Agrícola, UFCG, e-mail: jeronimoagro@ hotmail.com

${ }^{2}$ Prof. Doutor, Depto de Engenharia Agrícola, UFCG, e-mail: cazevedo@deag.ufcg.edu.br

${ }^{3}$ Prof. Doutor, Depto de Engenharia Agrícola, UFCG, e-mail: zedantas@ deag.ufcg.edu.br

${ }^{4}$ Mestrando em Manejo de Solo e Água, UFPB, e-mail: joabjosemar@gmail.com

${ }^{5}$ Doutorando em Engenharia Agrícola, UFCG, e-mail: neto_gouveia@ hotmail.com
}

\section{RESUMO}

O pinhão-manso (Jatropha curcas L.) é uma planta produtora de óleo atualmente considerada uma alternativa para produção de biodiesel. Objetivou-se com esta pesquisa avaliar os efeitos da aplicação de diferentes níveis de reposição da evapotranspiração, através da irrigação com água salina, e efeitos da adubação orgânica e mineral, sobre as concentrações de elementos nas folhas das plantas de pinhão manso, sob condições de campo. O experimento foi desenvolvido na Fazenda Barra, no município de Santa Luzia, no semiárido paraibano. O delineamento experimental utilizado foi em blocos casualizados, em um esquema de parcelas subdivididas, com quatro repetições. Foram estudados dois níveis de reposição de água (25 e $125 \%$ da evapotranspiração de referência) nas parcelas e três tipos de adubação (orgânica, mineral e fertilidade natural do solo, isto é, sem aplicação de adubo) nas subparcelas. As concentrações de fósforo, potássio e boro não foram influenciadas significativamente pelas lâminas de água ou pelas adubações aplicadas. As menores concentrações foliares de nitrogênio foram obtidas nas plantas que não receberam nenhuma adubação e foram irrigadas com menor lâmina de água. Nas plantas que receberam adubação orgânica ou mineral, as maiores concentrações foliares de sódio foram obtidas nas plantas que receberam a menor lâmina de irrigação.

Palavras-chave: Jatropha curcas L., salinidade, evapotranspiração.

\section{EFFECT OF FERTILIZATION TYPES AND WATER SALINA BLADES IN PHYSIC NUT LEAVES UNDER FIELD CONDITIONS}

\begin{abstract}
The physic nut (Jatropha curcas L.) is an oil producer plant currently considered an alternative for biodiesel production. The objective of this research was to evaluate the effects of different levels of replacement of evapotranspiration by irrigation with saline water, and effects of organic and mineral fertilizer on the concentrations of elements in the leaves of Jatropha curcas under field conditions. The experiment was carried out at Barra, in Santa Luzia, in the semiarid region of Paraíba. The experimental design was randomized blocks in a split plot with four replications. We studied two levels of water replacement (25 and $125 \%$ of reference evapotranspiration) in the plots and three types of fertilization (organic, mineral and
\end{abstract}




\section{EFEITO DE TIPOS DE ADUBAÇÃO E LÂMINAS DE ÁGUA SALINA \\ EM FOLHAS DE PINHÃO MANSO EM CONDIÇOES DE CAMPO}

natural soil fertility, ie without application of fertilizer) in subplots. The concentrations of phosphorus, potassium and boron were not significantly influenced by water replacement or the fertilizer applied. The lower leaf nitrogen concentrations were obtained in plants that received no fertilizer and were irrigated with less water depth. In plants that received organic manure or mineral, the highest leaf concentrations of sodium were obtained in plants that received less water depth.

Keywords: Jatropha curcas L., salinity, evapotranspiration.

\section{INTRODUÇÃO}

As facilidades do pinhão manso quanto a seu manejo agrícola e colheita das sementes, com relação a outras espécies, tornam essa cultura bastante atrativa e especialmente recomendada para um programa de produção de óleos vegetais. São muitas as vantagens econômicas e sociais do uso dessas plantas adaptadas ao clima semiárido, como elevação do nível de emprego, fixação do homem no campo, melhor distribuição da renda regional, geração de produtos de valor comercial e expressivas receitas e impostos, além de excelentes expectativas de mercado interno e externo, gerando divisas.

As águas de qualidade inferior, tais como águas de salinidade elevada, efluentes de processos industriais e de esgotos, particularmente os de origem doméstica, e águas de drenagem agrícola devem, sempre que possível, ser consideradas fontes alternativas para usos menos restritivos. $\mathrm{O}$ uso de tecnologias apropriadas para o desenvolvimento dessas fontes constitui-se, hoje, em conjunção com a melhoria da eficiência do uso e o controle da demanda, na estratégia básica para a solução do problema da falta universal de água (HESPANHOL, 2003).

A literatura disponível referente à cultura do pinhão-manso, ainda é bastante escassa, visto que pouco se conhece sobre a sua bioquímica e fisiologia; não existem cultivares definidas e alguns aspectos agronômicos ainda carecem de investigação como, por exemplo, a população ideal de plantas e a configuração de plantio, entretanto, com a possibilidade do uso do óleo do pinhãomanso para a produção do biodiesel, novas e amplas perspectivas se abrem para o aumento das áreas de plantio com esta cultura no semiárido nordestino (BELTRÃO, 2006).

A água é fator de fundamental importância para a produção de alimentos. A prática da irrigação é, em muitas situações, a única maneira de garantir a produção agrícola com segurança, sobretudo em regiões tropicais de clima quente e seco, como é o semiárido do Nordeste brasileiro, onde ocorre déficit hídrico para as plantas em virtude da taxa de evapotranspiração exceder a pluviosidade, durante a maior parte do ano. Diante do exposto, objetivouse neste trabalho, avaliar os efeitos das laminas de irrigação com água salina e tipos de adubação nos teores de elementos em folhas de pinhão manso.

\section{MATERIAL E MÉTODOS}

O trabalho foi realizado no Município de Santa Luzia-PB na Mesorregião da Borborema e na Microrregião do Seridó Ocidental Paraibano, caracterizada de acordo com a classificação climática de Koppen, adaptada ao Brasil (Coelho \& Soncin, 1982), tipo "Csa" por clima semiárido quente, temperatura oscilando entre $25^{\circ} \mathrm{C}$ e $28^{\circ} \mathrm{C}$ e precipitações pluviométricas médias anuais em torno de $550 \mathrm{~mm}$, com chuvas concentradas nos meses de janeiro a abril.

As sementes de pinhão foram plantadas em sacos de polietileno de $2 \mathrm{dm}^{3}$ em dezembro de 2007, e transplantadas para campo em abril de 2008, com espaçamento de 2x3 m. O sistema de produção do pinhão manso, em condições de campo, foi irrigado com sistema de irrigação por gotejamento sendo a água salina, da classe $\mathrm{C}_{4}$ de acordo com RICHARDS (1954), proveniente de um 


\section{EFEITO DE TIPOS DE ADUBAÇ̃̃o E LÂMINAS DE ÁGUA SALINA}

EM FOLHAS DE PINHÃO MANSO EM CONDIÇOES DE CAMPO

poço tipo Amazonas, construído no Riacho Barra.

Foram testadas cinco lâminas de irrigação (L), e três tipos de adubos (orgânico, mineral e fertilidade natural do solo). As lâminas foram definidas através da evaporação de um tanque Classe A, instalado próximo à área experimental, adotando-se os índices: $\mathrm{L}_{1}=0,25$ e $\mathrm{L}_{2}=$ 1,25 da evaporação do tanque Classe A. A adubação mineral consistiu da aplicação de $180 \mathrm{~g} /$ planta do adubo com formulação 624-12 e a adubação orgânica foi realizada aplicando-se $10 \mathrm{~L} /$ planta de esterco bovino curtido.

Os tratamentos lâmina de água de irrigação (L) e adubação (A) foram combinados, resultando em 6 tratamentos $(2 \times 3)$, com quatro repetições, distribuídos em blocos casualizados em esquema de parcela subdividida. Nas parcelas estavam dispostas as lâminas de água de irrigação e nas subparcelas os tipos de adubação.

Coletaram-se, para as amostras de folhas, limbos foliares expandidos localizados entre a sexta e a oitava folha abaixo da inflorescência das plantas, aos 360 dias após o plantio . As análises dos elementos $\mathrm{N}, \mathrm{P}, \mathrm{K}, \mathrm{Na}$ e $\mathrm{B}$ foram realizadas no Laboratório de Tecido de Planta da UFPB/CCA, Areia, PB, seguindo-se as metodologias propostas por Tedesco (1995). A amostragem privilegiou folhas normais, sadias, sem deficiência nutricional aparente ou ataque de pragas ou doenças.

Os resultados das concentrações dos elementos foram submetidos à análises de variância, pelo teste $\mathrm{F}(\mathrm{P}<0,05) \mathrm{e}$ comparação de médias pelo teste de Tukey $(\alpha<0,05)$ (GOMES, 1982; SANTOS et al., 2003). Todas as análises foram realizadas utilizando-se o software SISVAR, versão 4.6 (FERREIRA, 2003).

\section{RESULTADOS E DISCUSSÃO}

Não houve efeito significativo das lâminas de irrigação (L) sobre as concentrações de fósforo, potássio e boro, pelo teste $\mathrm{F}(\mathrm{P}<$
0,05). Entretanto, verificou-se efeito desses tratamentos sobre as concentrações de nitrogênio e sódio, a $1 \%$ de probabilidade, pelo teste $\mathrm{F}$ (Tabela 1). Os tratamentos de adubação (A) não alteraram significativamente $(\mathrm{P}<0,05)$ as concentrações de nenhum dos elementos avaliados. Constatou-se efeito significativo, a $5 \%$ pelo teste $\mathrm{F}$, da interação L x A sobre as concentrações de $\mathrm{N}$ e $\mathrm{Na}$.

A ordem de acúmulo de nutrientes nas folhas, de maneira geral, foi a seguinte: $\mathrm{N}$ $>\mathrm{Na}>\mathrm{K}>\mathrm{P}>\mathrm{B}$, concordando com os resultados obtidos por Saturnino et al. (2005). Com relação aos macronutrientes, Laviola e Dias (2008), verificaram a seguinte ordem de acúmulo, em folhas de plantas de pinhão manso: $\mathrm{N}>\mathrm{K}>\mathrm{P}$, similar à encontrada neste experimento.

As concentrações foliares de macronutrientes foram superiores às observadas por Beltrão et al. (2007), que coletaram todas as folhas de uma planta de 100 dias, para análise química.

$\mathrm{Na}$ Tabela 2, quando se compara o desdobramento dos diferentes tipos de adubação em função das lâminas de água de irrigação, verificou-se que na reposição de $25 \%$ da ETo o maior teor de nitrogênio na folha $\left(34,50 \mathrm{~g} \mathrm{~kg}^{-1}\right)$ ocorreu na adubação orgânica, não se diferenciando da adubação mineral. Nas plantas que receberam $125 \%$ da ETo, não houveram diferenças estatísticas significativas em relação aos tipos de adubação utilizados, com uma média de $25,91 \mathrm{~g} \mathrm{~kg}^{-1}$. Analisando o desdobramento das lâminas de água de irrigação em cada tipo de adubação, constatou-se que sem a adubação (fertilidade natural do solo) não houve efeito na concentração do nitrogênio foliar, independente da quantidade de água aplicada; já na adubação orgânica e na adubação mineral, obteve-se os maiores teores foliares de nitrogênio com a aplicação de $25 \%$ da ETo. Na reposição de $125 \%$ da ETo, pode ter ocorrido lixiviação deste nutriente, resultando em baixa absorção pelas plantas. 


\section{EFEITO DE TIPOS DE ADUBAÇÃO E LÂMINAS DE ÁGUA SALINA

Tabela 1. Resumo das análises de variância e médias de teores de elementos em folhas de pinhão-manso irrigado com água salina e adubado.

\begin{tabular}{|c|c|c|c|c|c|c|}
\hline \multirow{2}{*}{ Fonte de variação } & \multirow[t]{2}{*}{ G.L. } & \multicolumn{5}{|c|}{ Quadrados Médios } \\
\hline & & $\mathrm{N}$ & $\mathrm{P}$ & $\mathrm{K}$ & $\mathrm{Na}$ & $\mathrm{B}$ \\
\hline Blocos & 3 & $6,33 \mathrm{~ns}$ & $0,16 \mathrm{~ns}$ & $7,04 \mathrm{~ns}$ & $1943041,26 \mathrm{~ns}$ & $93,00 \mathrm{~ns}$ \\
\hline Lâminas (L) & 1 & $204,16^{* *}$ & $0,16 \mathrm{~ns}$ & $92,04 \mathrm{~ns}$ & $20172167,04 *$ & $704,16 \mathrm{~ns}$ \\
\hline Resíduo (a) & 3 & 2,94 & 0,61 & 16,70 & 1547045,37 & 131,16 \\
\hline Adubação (A) & 2 & $31,79 \mathrm{~ns}$ & $0,29 \mathrm{~ns}$ & $10,29 \mathrm{~ns}$ & $7061240,62 \mathrm{~ns}$ & $347,04 \mathrm{~ns}$ \\
\hline $\mathbf{L} \times \mathbf{A}$ & 2 & $44,04 *$ & $0,54 \mathrm{~ns}$ & $32,29 \mathrm{~ns}$ & $10191168,79 *$ & $310,04 \mathrm{~ns}$ \\
\hline Resíduo (b) & 4 & 8,47 & 0,47 & 12,79 & 2133831,31 & 296,20 \\
\hline C.V. (a) \% & - & 5,95 & 19,14 & 18,20 & 18,74 & 21,54 \\
\hline C.V. (b) \% & - & 10,09 & 16,83 & 15,93 & 22,01 & 32,37 \\
\hline \multicolumn{7}{|c|}{ Médias para as Lâminas de Água de Irrigação } \\
\hline $25 \%$ da ETo & & $31,75 \mathrm{a}$ & $4,16 \mathrm{a}$ & $24,41 \mathrm{a}$ & $7554,41 \mathrm{a}$ & $47,75 \mathrm{a}$ \\
\hline $125 \%$ da ETo & & $25,91 \mathrm{~b}$ & $4,00 \mathrm{a}$ & $20,50 \mathrm{a}$ & $5720,83 \mathrm{~b}$ & $58,58 \mathrm{a}$ \\
\hline \multicolumn{7}{|c|}{ Médias para Adubação $\left(\mathrm{g} \mathrm{kg}^{-1}\right)$} \\
\hline Sem Adubação & & $27,87 \mathrm{a}$ & $4,12 \mathrm{a}$ & $23,75 \mathrm{a}$ & $7410,75 \mathrm{a}$ & $48,87 \mathrm{a}$ \\
\hline Adubação Orgânica & & $31,12 \mathrm{a}$ & $3,87 \mathrm{a}$ & $22,00 \mathrm{a}$ & $6910,12 \mathrm{a}$ & $49,87 \mathrm{a}$ \\
\hline Adubação Mineral & & $27,50 \mathrm{a}$ & $4,25 \mathrm{a}$ & $21,62 \mathrm{a}$ & $5592,00 \mathrm{a}$ & $60,75 \mathrm{a}$ \\
\hline
\end{tabular}

Tabela 2. Médias do desdobramento da interação LxA para o nitrogênio ${ }^{1}$.

Desdobramento do fator lâmina de água de irrigação em cada tipo de adubação

\begin{tabular}{cccc}
\hline Lâminas & Sem adubação & Adubação orgânica & Adubação mineral \\
$25 \%$ & $28,25 \mathrm{aB}$ & $34,50 \mathrm{aA}$ & $32,50 \mathrm{aA}$ \\
$125 \%$ & $27,50 \mathrm{aA}$ & $27,75 \mathrm{bA}$ & $22,50 \mathrm{bA}$
\end{tabular}

${ }^{T}$ Médias seguidas da mesma letra minúscula na coluna e maiúscula na linha não diferem estatisticamente pelo teste Tukey a $5 \%$ de probabilidade

$\mathrm{Na}$ Tabela 3, verifica-se o desdobramento dos diferentes tipos de adubação em cada um dos níveis de reposição da ETo, para a concentração foliar de sódio. Não houve diferença estatística significativa, pelo teste de Tukey a 5\% de probabilidade, na lâmina de água de irrigação com $25 \%$ da ETo, entre os tratamentos de adubação, com uma média de 7554,41 $\mathrm{mg} \mathrm{kg}^{-1}$. $\mathrm{Na}$ reposição de $125 \%$ da ETo, as maior concentração de sódio nas folhas foram obtida quando as plantas não receberam nenhum tipo de adubação ou receberam adubação orgânica. 
EFEITO DE TIPOS DE ADUBAÇÃO E LÂMINAS DE ÁGUA SALINA

EM FOLHAS DE PINHÃO MANSO EM CONDIÇOES DE CAMPO

Tabela 3. Médias do desdobramento da interação LxA para o sódio ${ }^{1}$.

Desdobramento do fator lâmina de água de irrigação em cada tipo de adubação

\begin{tabular}{cccc}
\hline Lâminas & Sem adubação & Adubação orgânica & Adubação mineral \\
$25 \%$ & $7104,25 \mathrm{aA}$ & $8049,25 \mathrm{aA}$ & $7509,75 \mathrm{aA}$ \\
$125 \%$ & $7717,25 \mathrm{aA}$ & $5771,00 \mathrm{bAB}$ & $3674,25 \mathrm{bB}$
\end{tabular}

${ }^{1}$ Médias seguidas da mesma letra minúscula na coluna e maiúscula na linha não diferem estatisticamente pelo teste Tukey a $5 \%$ de probabilidade

\section{CONCLUSÕES}

As concentrações de fósforo, potássio e boro não foram influenciadas significativamente pelas lâminas de água ou pelas adubações aplicadas.

As menores concentrações foliares de nitrogênio foram obtidas nas plantas que não receberam nenhuma adubação e foram irrigadas com menor lâmina de água.

Nas plantas que receberam adubação orgânica ou mineral, as maiores concentrações foliares de sódio foram obtidas nas plantas que receberam a menor lâmina de irrigação.

\section{REFERÊNCIAS BIBLIOGRÁFICAS}

BELTRÃO, N. E. M. Considerações gerais sobre o pinhão-manso (Jatrofha curcas L.) e a necessidade urgente de pesquisas, desenvolvimento e inovações tecnológicas para esta planta nas condições brasileiras. Campina Grande, PB, 2006. 4p. Disponível em:<http://www.mda.gov.br>. Acesso em: 25 de março de 2010

BELTRÃO, N.E.M.; LIMA, R.L.S.; SEVERINO, L.S.; SAMPAIO, L.R.; SOFIATTI, V. \& LEÃO, A.B. Crescimento e acúmulo de nutrientes pelo pinhão-manso sob interferência de plantas daninhas. In: Congresso Brasileiro de Plantas Oleaginosas, Óleos, Gorduras e Biodiesel, 4., Varginha. Anais... Lavras: UFLA, 2007. p.1892-1900.

TEDESCO, M. J.; GIANELLO, C.; BISSANI, C. A.; BOHNEN, H. \& VOLKWEISS, S. J. Análises de solo, plantas e outros materiais. 2. ed. UFRGS. Porto Alegre, RS, 1995. 174p

COELHO, M.A.; SONCIN, N.B. Geografia do Brasil. São Paulo: Moderna. 1982. 368 p.

FERREIRA, D. F. SISVAR software: Versão 4.6. Lavras: DEX/UFLA, 2003. Software.

GOMES, P. Adubos e adubações. 12. ed. São Paulo: Nobel, 1982. 187p.

HESPANHOL, I. Potencial de reúso de água no Brasil: agricultura, indústria, municípios, recarga de aqüíferos. In: MANCUSO, C. S. A.; SANTOS, H. F. (Editores). Reúso de Água. Barueri: Manole, 2003. cap. 3 p. 3795.

LAVIOLA, B; G.; DIAS, L. A. S. Teor e acúmulo de nutrientes em folhas e frutos de pinhão-manso. Revista Brasileira de Ciências do Solo, v.32, p.1969-1975, 2008.

RICHARDS, L.A. Diagnosis and improvement of saline and alkali soils. Washington: US Department of Agriculture, 1954. 160p.

SANTOS, J. W. dos; GHEYI, H. R. Estatística Experimental Aplicada: Tópicos de Engenharia Agrícola e Agronômica. Campina Grande: Ed. Gráfica Marcone, 2003. 213p.

SATURNINO, H. M.; PACHECO, D. D.; KAKIDA, J. TOMINAGA, N.; GONÇALVES, N.P. Cultura do pinhão manso (Jatropha curcas L.). In: Informe Agropecuário, Belo Horizonte, EPAMIG, $\begin{array}{lll}\text { v.26, } & \text { n.229, } & \text { p.44-78, } 2005\end{array}$ 